\title{
International Monetary Policy \\ Coordination in a New Keynesian Model with NICE Features
}

\author{
Jean-Christophe Poutineau* \\ Gauthier Vermandel $^{* *}$
}

This paper provides a static two country new Keynesian model to teach two related questions in international macroeconomics: the international transmission of unilateral monetary policy decisions and the gains coming from the coordination monetary rules. We concentrate on "normal times" and use a thoroughly graphical approach to analyze the questions at hands. In this setting monetary policy is conducted using interest rates rules and economic integration between nations does not necessarily create the case for the coordination of monetary policy. In particular, we show that the conduct of optimal national monetary policies does not make any difference with the coordination of national policies, as this creates a situation where the international monetary system operates "Near an International Cooperative Equilibrium" (NICE).

JEL codes: A20, E10, E50, F41.

Keywords: monetary policy, New Keynesian macroeconomics, international macroeconomics, economic policy, optimal interest rate rules.

* Corresponding author: jean-christophe.poutineau@univ-rennes1.fr, +3322323 33 58. CREM, UMR CNRS 6211, University of Rennes, Rennes, France.

** University of Paris Dauphine, PSL Research University, Paris, France. Email: gauthier@vermandel.fr

We thank William Walstad, David Colander and four anonymous referees for helpful comments that allowed us to improve the initial version of this paper. We thank Louise Rimbert and Anais Moison for skillfull assistance. An extended version of this paper (with analytical appendices) is available at the following address: https://sites.google.com/view/poutineau/research. We remain responsible for any errors and omissions. 
The rise in cross border trade and financial flows has made policy decisions more sensitive to international developments, meanwhile increasing their global spillovers. This question clearly matters for monetary policy, as the size of cross border effects channeled by the exchange rate market may provide incentives to coordinate interest rate decisions between central banks. However, addressing this topic in intermediate macroeconomics courses is difficult, as standard Keynesian macroeconomic models often used in teaching monetary policy issues at the undergraduate level are at odds with state of the art models used in graduate education as well as in central banks.

The story presented in intermediate macroeconomics courses is usually framed in a two country version of the Mundell-Fleming model. It goes as follows: a central bank increases its money supply which depreciates national terms of trade. As exports become more competitive, the current account surplus improves and national activity increases through the "expenditure switching effect". Meanwhile, the foreign country suffers from a "beggar thy neighbor" situation, since the increase in the relative price of its goods decreases its exports and activity. As this negative terms of trade externality may lead to a currency war, the coordination of monetary decisions may be a first best solution. ${ }^{1}$

As a commonly recognized problem, this story is at odds with the standard practice of monetary policy in normal times. First it assumes that central banks control their money supply and ignores that conventional monetary policy practices are set on interest rate rules. Second it provides a simple theoretical result to favor the coordinated monetary policy decisions that contrasts with empirical findings. As underlined by Blanchard et al. (2013), "examples of international macro policy coordination have been few. The most successful cases have been when the world economy seemed on the brink of collapse. In more normal times, despite strong theoretical arguments and evident systemic stresses, policymaking takes a national rather than multilateral perspective." Indeed, if at the onset of the recent financial 
crisis coordinated joint interventions of central banks were able to reduce short run interest rates in october 2008, the current unwinding of unconventional monetary policy measures conducted by the Federal Reserve is characterised by a unilateral perspective based on the improvement of the US situation. As usually observed in "normal times" this decision neglects possible negative spillovers on foreign economies still trapped in the Zero Lower Bound.

This paper contributes to the literature seeking to make the undergraduate teaching of macroeconomics better aligned with the modern practice of implementing monetary policy in the open economy. It extends existing undergraduate instructional technology in a way that accommodates results and observations about the lack of monetary policy coordination found in the professional discourse despite the deepening financial integration between nations. We more particularly propose a static model consisting as an extension of the BMW model introduced by Bofinger et al. $(2006,2009)$ to a two country world. We concentrate on "normal times" and assume that monetary policy is implemented in a conventional way using an interest rate rule. To make the paper better suited to advanced undergraduate student instruction, we use a thoroughly graphical approach.

Our paper analyses two related questions. First, we describe the nature of international spillovers under simple interest rules. We provide a simple exposition of the way asymmetric interest rate decisions, demand and inflation shocks create international spillovers. This analysis shows how international cross border trade and financial flows combine pecuniary (terms of trade fluctuations) and non-pecuniary (income effects) externalities that may create "beggar thy neighbor" situations. Second, we analyse the coordination of monetary policy as the outcome of an optimal monetary policy choice. We show that under optimal interest rate rules the Non cooperative and cooperative solutions are isomorphic: the conduct of optimal national monetary policies does not make any difference with the coordination of national policies, as this creates a situation where the international monetary system operates "Near 
an International Cooperative Equilibrium" (NICE). ${ }^{2}$ This result - that contrasts with the one observed in an extended Mundell-Fleming model - corresponds to the situation described by Taylor (2013) and provides a simple reason for understanding why "International policy coordination is like the Loch Ness monster: much discussed but rarely seen." (Blanchard et al., 2013).

Beneath this focus on a standard question related to the conduct of monetary policy in a globalized world, our paper offers a consistent two country model that accounts for the way decisions undertaken by a big country affects the macroeconomic situation of other nations. Our framework can be extended to present different questions requiring an international (rather than a simple open-economy) macroeconomics perspective at the undergraduate level. As non-exclusive examples, our analysis can be adapted to study the working of exchange regimes, the international transmission of fiscal policies, the consequences of structural and asymmetries on international adjustment...

The rest of the paper is organized as follows. Section II presents the background of the analysis by providing a simple perspective on the topic at hands and introduces the model. Beneath this presentation, we discuss the main modelling choices required to keep the model as simple as possible while acounting for the different channels of structural interdependence between economies. Section III analyses the international consequences of unilateral interest rate decisions and discusses the properties of such rules following asymmetric demand and inflation shocks in a "New Keynesian" world. Section IV discusses the implementation of optimal interest rate rules and provides a simple approach to the NICE result underlying the absence of welfare gains associated to the coordination of optimal interest rate decisions. Section V concludes. 


\section{BACKGROUND}

This section presents in simple terms elements that are important to convey the basic insights of the problem at hands to undergraduate students and introduces a two-country version of the BMW model (Bofinger et al., 2006 and 2009).

\section{Globalization, spillovers and monetary policy coordination}

Do increased international trade and financial connections favor the coordination of national monetary policy decisions? The rise in cross border trade and financial flows has made policy decisions more sensitive to international developments, meanwhile increasing the global spillovers of monetary and fiscal national decisions. This question is particularly sensitive for the conduct of monetary policy, as national policy-makers targeting domestic objectives may reach a collectively suboptimal Non cooperative equilibrium at the world level. For example, a central bank may undertake looser policy decisions to depreciate national terms of trade and make exports become more competitive. This improves the current account surplus and national activity increases through the "expenditure switching effect". However, this unilateral decision has spilovers effects on neighbouring countries that may suffer from a "beggar thy neighbor" situation as the increase in the relative price of their goods decreases its exports and activity.

In a medium run perpective, neighbor countries may eventually adopt similar looser interest rate decisions which creates a currency war without any net winner, as the terms of trade suffer from opposite forces. Eventually, this repeated game of currency depreciation should make all countries worse off, as the global increase in money supply will increase inflation without net activity gains. 
The spillover effects of monetary policy channeled by capital flows and exchange rate movements, can be large. Concern for these effects may place constraints on the conduct of monetary and provides a rationale for adopting coordinated policy decisions. However, this outcome is scarcely observed in reality. As rencently underlined by Coeure (2016), Frankel (2016) or Ostry and Ghosh (2016), only a few historical examples - corresponding to situations of trouble times - are worth noting: the 1978 Bonn Summit, the 1985 Plaza Agreement, and the 1987 Louvre Accord. Major decisions favouring a mutilateral management of monetary policy have been undetaken when the world economy seemed closed to a collapse: the 1987 stock market crash, the joint liquidity provision by major central banks after the $9 / 11$ events when the G-7 coordinated interest rate cuts and liquidity provision, and the 2008 global financial crisis, where major central banks decided on a coordinated policy rate reduction on the 8th October 2008.

Nevertheless, the adoption of coordination measures is rather an exception than a rule. As a recent example, the unilateral decision of the Federal Reserve board to go back to a "new normal" by increasing its short term interest rate neglects the fact that other major central banks have not yet began to unwind unconventional monetary policies. This situation raises natural questions in the classroom to evaluate the global consequences of such a unilateral decision owing to the weight of US economy at the world level.

Why, despite increased interdependence, coordinated monetary policy decisions are that few? To analyse this question in the clasroom, one needs models that explicitely provide international trade and financial channels between economies. As underlined by Daniels and Van Hoose (1998), two-country models provide a natural approach to the consideration of open-economy policy issues where the sources of interdependence must be explicitly taken into account. On the pedagogical side, the use of such model is illustrated in textbooks such as Feenstra and Taylor (2017). However, the extended mundellian framework traditionnaly 
used is at odds with monetary policy practices based on short run interest rate management and it neglects the inflation consequences of the strategic manipulation of exchange rate.

Teaching the conduct of monetary policy in interdependent economies lacks a up to date description of policy choices based on interest rate setting, such as it is the case in normal times, to understand why coordination episodes are that few. Our objective is to fill this gap by providing a two country version of the BMW framework.

\section{A two country BMW model}

The BMW model is one possible framework for teaching modern macroeconomics in a static environment. ${ }^{3}$ This model partly draws on the simplified version of the New Keynesian model introduced by Walsh (2002) to present the main features of inflation targeting in a pre-crisis environment. The key elements of the model in a closed economy are presented by Bofinger et al. (2006) to introduce the students to the debate between simple and optimal monetary rules and assess the consequences of fiscal policy. Bofinger et al. (2009) provide an extension of the basic "three equation new keynesian" model to the case of a small open economy. More recently, Poutineau and Vermandel (2015) extend the basic three equation model to the case of the financial accelerator - and treat questions related to the conduct of macroprudential policy in line with monetary policy - while Buttet \& Roy (2014) offer a simple treatment of the question of conduct of monetary policy at the zero lower bound.

In this paper we provide a further extension of the BMW model to a two country environment to evaluate the channels of interdependence between economies. Bofinger et al. (2009) focus on a small open economy with national policy decisions having no effect on the world's macroeconomic equilibrium. This partial equilibrium approach only discusses part of the consequences of monetary policy decisions in an integrated global economy. A two country approach allows for an impact of domestic choices on the outside world, which better fits the 
reality of US or Eurozone monetary policy decisions. In particular, it provides a more general approach to the conduct of monetary policy that accounts for possible negative externalities between countries coming from a strategic manipulation of the interest rate.

We assume that the world is made of two symmetric economies interacting through trade and financial linkages: Capital is mobile internationally, the exchange rate is flexible and countries implement independent monetary policy following a Taylor-type interest rate rule. As depicted in Table 1, the model consists of eight equations organized along three building blocks: two internal equilibria (that consist of IS, MP and PC relations) and an international part (a FX condition for the exchange rate market and a TOT relation that defines the Terms Of Trade). The two parts of the world are symmetric in that they have the same relative weight and share the same parameter values. In what follows, we describe the domestic part of the model (as the foreign component is isomorphic, except that variables are noted with a “*”).

The structures of the Phillips curve (PC) and of the monetary policy rule (MP) are standard to static versions of the New Keynesian macroeconomic model. In the new Keynesian Phillips Curve, is the rate of inflation, y is the output gap, and $\varepsilon_{S}$ is a cost-push (inflation) shock (a positive realization of this shock describes an exogenous increase in goods prices). As in Bofinger et al. (2006), we assume that monetary policy is credible (so that inflation expectations are based on the targeted inflation rate, assumed to be equal to 0\%) which makes the $\mathrm{PC}$ relation static. Parameter $\beta$ is the elasticity of inflation to the output gap.

Regarding monetary policy, authorities control the policy relevant interest rate, r, according to a Taylor rule. Here, $\gamma_{1}$ is the elasticity of the interest rate to the inflation rate. In this setting "good policy" obeys to the Taylor principle: Nominal interest rates are adjusted more than one-for-one with deviations of inflation from an inflation target (ie, $\left.\gamma_{1} 1\right)$. 
Parameter $\gamma_{2}$ is the elasticity of the interest rate to the output gap. Variable $\varepsilon_{R}$ is an exogenous interest shock (a positive realization of this shock rises the policy rate, thus depicting an unexpected tightening of monetary conditions in the economy).

[Insert Table 1 about here]

The IS (IS*) relation combines domestic and international components. It links the output gap to national demand and to the current account surplus/deficit. On the domestic side, we account for interest rate changes on the output gap with elasticity - $\alpha_{1}$ (the key channel for the transmission of monetary policy decisions to affect inflation though this gap) and assume that the demand shock, $\varepsilon_{D}$ summarizes all exogenous influences on the output gap. Although the IS curve traditionally includes government spending and taxation, we adopt a standard approach of the NK model with fiscal policy generally being characterized as one of the elements in the central banks' policy environment. ${ }^{4}$

The international part is summarized by the current account. The current account (CC) takes into account two main determinants: an expenditure switching effect (related to $q$, the terms of trade) and an relative income effect (related to the difference between the output gap of the domestic vs. output gap of the foreign country $\left.\left(y^{*}-y\right)\right)$,

$$
C C=\alpha_{2} q+\alpha_{3}\left(y^{*}-y\right) .
$$

The first effect takes into account the fluctuations in the terms of trade (namely the relative price of foreign goods in terms of domestic goods) as a positive contributor to the current account (as an increase in $q$ makes imports more expensive while domestic goods are cheaper abroad), with elasticity $\alpha_{2}$. The value of $\alpha_{2}$ measures the strength of the "consumption switching effect" that plays a key role in the Mundell-Fleming model. In log deviation with respect to the steady state, the terms of trade is simply equal to the sum of the nominal exchange rate and the foreign inflation rate minus the domestic inflation rate, 


$$
q=e+\pi^{*}-\pi
$$

The second determinant of the current account depends on the difference between the output gap of the domestic vs. output gap of the foreign country $\left(y^{*}-y\right)$, to capture the effect of national income in the determination of the net value of imports. An net increase in the foreign output gap over the domestic one has a positive effect on domestic exports (and on the current account) while an net increase in the domestic output gap over the foreign one has a positive effect on domestic imports (and thus a negative effect on the current account). For simplicity, these variables affect the current account with the same elasticity given by parameter $\alpha_{3}$.

This model accounts for a formal definition of the Foreign Exchange (FX) market equilibrium under perfect capital mobility based on the Uncovered Interest Parity (UIP). The FX equilibrium links the variations in the terms of trade to the interest rate differential between countries. The nature of this relation can be explained as follows: under perfect capital mobility, the equilibrium of the exchange rate market requires that, for a given period t,

$$
r_{t}=r_{t}^{*}+\mathrm{E}_{t}\left(e_{t+1}\right)-e_{t}
$$

To allow for a static interpretation of UIP, we introduce an expectation formation rule based on a comparison between the current nominal rate and the Purchasing Power Parity value. Formally, we assume that agents expect the evolution of the exchange rate between two periods (say between $t+1$ and $t$ ) as a correction between the current exchange rate observed on the market and its PPP value (that forms the long run equilibrium). ${ }^{5}$ Assuming that the speed of convergence of the exchange rate to PPP is $\phi$, we can write,

$$
\mathrm{E}_{t}\left(e_{t+1}\right)-e_{t}=-\phi\left(e_{t}-e_{P P P}\right) \text {. }
$$

Thus, if the value of the exchange rate exceeds the PPP benchmark $\left(\left(e_{t}-e_{P P P}\right)>0\right)$, the domestic currency is relatively depreciated with respect to its long run value. In this case, 
agents expect that the currency will appreciate in the next periods to catch up its long run equilibrium value $e_{P P P}$, at speed $\phi$. In the very special case where $\phi=1$, the exchange rate will be equal to its long run value in the next period. In more general situations, $\phi$ is much lower than one. Following the relative PPP theory, we know that $e_{P P P}=\pi-\pi *$. Thus combining the UIP with the relative PPP and defining the terms of trade (TOT) as, $q=e+\pi^{*}-\pi$, we get the expression of the exchange rate market equilibrium FE reported in Table 1.

Graphically, this model can be depicted along a four panel graph presented in Figure 1. For each country, the equilibrium combines two graphs introduced in the analysis by Bofinger et al. (2006) (panels a and b for the domestic economy and panels c and d for the foreign economy). In both countries, the initial equilibrium is represented at point A (resp. $A^{*}$ ) in the output gap / inflation rate space and at point A' (resp. A*') in the output gap / interest rate space. The upper panel combines the PC curves with Aggregate Demand (AD) schedules. The AD schedules are obtained by combining the IS and MP curves in each country. The expression of the $\mathrm{AD}$ and $\mathrm{AD}^{*}$ relations are thus:

$$
\begin{gathered}
A D: y=\frac{\alpha_{3} y^{*}+\alpha_{2} q}{1+\alpha_{1} \gamma_{2}+\alpha_{3}}-\frac{\alpha_{1} \gamma_{1}}{\left(1+\alpha_{1} \gamma_{2}+\alpha_{3}\right)} \pi+\frac{\varepsilon_{D}-\alpha_{1} \varepsilon_{R}}{\left(1+\alpha_{1} \gamma_{2}+\alpha_{3}\right)}, \\
A D^{*}: y^{*}=\frac{\alpha_{3} y-\alpha_{2} q}{1+\alpha_{1} \gamma_{2}+\alpha_{3}}-\frac{\alpha_{1} \gamma_{1}}{\left(1+\alpha_{1} \gamma_{2}+\alpha_{3}\right)} \pi^{*}+\frac{\varepsilon_{D}^{*}-\alpha_{1} \varepsilon_{R}^{*}}{\left(1+\alpha_{1} \gamma_{2}+\alpha_{3}\right)} .
\end{gathered}
$$

The adjustment in the terms of trade is not presented in the figure, but lies at the center of the analysis. It determines both the trade channel through the expenditure switching effect and the financial adjustment, through the uncovered interest rate parity.

Modeling international macroeconomic relations offers numerous possibilities. In this setting two modelling assumptions have been chosen to provide a description of the world economy that is mostly in line with major textbooks. First, the Mundell-Fleming model taught in undergraduate classes assumes a strong expenditure switching effect (captured in our model 
by a high value of $\alpha_{2}$ ); in our model a key element governing the international transmission of interest rate reaction is related to the strength of the expediture switching effect. In particular, we assume that the effect of the terms of trade on the current accounts dominates the income effects.

A second element concerns the inflation measure used in the paper. In an open economy, the distinction between overall consumer prices and prices of domestic goods (i.e., wholesale/producer prices) can be an important one (see e.g., Gali and Monacelli, 2005). To simplify computational and expository aspects, we follow the modelling choice of Carlin and Soskice (2015, page 324) to concentrate on the producer rather than on the consumer price. As a main pedagogical advantage, it directly links the inflation measure adopted by the central bank to the definition used in the Philips curve. This choice has no fundamental consequence on our main results even if we are aware that we neglect second round effects of exchange rate fluctuations on central bank inflation target. 


\section{INTERNATIONAL SPILLOVERS UNDER SIMPLE IN- TEREST RATE RULES}

In this section we discuss the international transmission of shocks originating in the home economy. National shocks are transmitted abroad via the trade channel that combines both a pecuniary externality (the terms of trade adjustment that follows interest rate decisions and affects the expenditure switching effect) and a non-pecuniary externality (the income effect on the current account). The first subsection - devoted to unilateral interest rate fluctuations - can be understood as a comparable exercice as the one conveyed for the international diffusion of a money supply increase in a two country Mundell-Fleming model (see for example Feenstra and Taylor (2017) for a discussion of this question). The second and third subsection focus on asymmetric demand and inflation shocks when national authorities follow Taylor rules.

\section{Unilateral interest rate fluctuations}

To understand how central bank reactions create international spillovers, we report the consequences of an exogenous decrease in the domestic interest rate in figure 1. A loosening of monetary policy can be represented through a negative shock on the domestic interest rate. In this situation the MP schedule moves rightwards (from MP to MP'), and the closed open economy equilibrium from A to B in the (y,r) space. This shock has a positive impact on AD that moves rightwards to AD'. The new equilibrium reached in the economy is B.

However, point $\mathrm{B}$ corresponds to a closed economy situation. In the open economy, the MP shock has further consequences on the equilibrium of both countries through the FX channel. The domestic decrease in the interest rate affects the foreign economy through a depreciation of the real exchange rate. Assuming that the expenditure switching effect related 
to the terms of trade adjustment dominates the income effect, the international trade channel induces an increase in domestic exports, while foreign exports decrease. ${ }^{6}$

[Insert Figure 1 about here]

In Figure 1, the decrease in the domestic interest rate affects the foreign economy as a demand shock (a decrease in exports towards the domestic economy) that shifts the IS* curve leftwards to IS*'. This phenomenon has a negative effect on both the foreign output gap and inflation rate. As a consequence, foreign monetary authorities must decrease their interest rate to dampen the decrease of foreign activity ( $\mathrm{MP}^{*}$ moves rightwards to $\mathrm{MP}^{*}$ '). This policy reaction finally leads to a leftward shift of the foreign aggregate demand schedule from $\mathrm{AD}^{*}$ to $\mathrm{AD}^{*}$. Thus in the final equilibrium (points $\mathrm{B}^{*}$ and $\mathrm{B}^{* \prime}$ ) the foreign economy experiences a negative output gap, deflation and a decrease in its nominal interest rate.

The equilibrium of the domestic economy is also affected by the adjustment of the terms of trade. As it exports more goods (through the positive expenditure switching effect), the IS curve shifts rightwards (from IS to IS'). The adjustment of the goods market leads to an increase in the inflation rate, which in turn affects the MP curve (that moves leftwards from MP' to MP"'). By so, the AD curve moves once more rightwards (from AD' to AD"). Once all adjustments have occurred, the final equilibrium of the model lies on point $\mathrm{C}$ for the domestic economy and on point $\mathrm{B}^{*}$ for the foreign economy. As observed, the international transmission of the interest rate reduction acts as a negative externality, as foreign activity falls while the domestic economy experiences a further increase in activity through a current account surplus. This negative externality is commonly referred to as a "beggar thy neighbor" situation because the extra domestic activity stimulus comes at the expense of other countries. 


\section{A Domestic Demand Shock}

The consequences of a positive demand shock (corresponding for example to a fiscal expansion) in the domestic economy are depicted in Figure 2. The national consequences of this shock in a closed economy have already been documented (Bofinger et al., 2006): it leads to a proportional shift of the IS curve rightwards (from IS to IS'). As this creates inflation, monetary policy reaction requires an interest rate increase, that shifts the MP curve leftwards (from MP to MP'). Combining both effects, the $\mathrm{AD}$ curve shifts rightwards (from $\mathrm{AD}$ to AD'), but less than proportionally to the demand shock due to the interest rate reaction. [Insert Figure 2 about here]

In the open economy, this shock has further effects through the adjustment of the terms of trade and the income consequences of the shock on the current account of both countries. Following the increase in the domestic interest rate, the real exchange rate decreases (domestic currency appreciates in real terms). The expenditure switching effect related to the decrease in the terms of trade is reinforced by the effect of an increase of domestic income on foreign exports, and the IS* curve moves rightwards (from IS* to IS*'). As for the domestic economy, this positive demand shock (channeled through the current account) leads to a tightening of monetary policy in the foreign economy (an increase in the foreign interest rate) that shifts MP* leftwards to MP*'. Finally, combining both effects on IS* and MP*, the $\mathrm{AD}^{*}$ curve moves rightwards (from $\mathrm{AD}^{*}$ to $\mathrm{AD}^{*}$ ). Thus the domestic exogenous positive demand shock implies an increase in the output gap, the inflation rate and the interest rate in the foreign economy.

The international adjustment of the world economy has a further impact in the domestic country. As the domestic currency appreciates in real terms, exports towards the foreign economy decrease (which implies a correcting IS leftward shift from IS' to IS") and, as a byproduct, a relative decrease in the domestic interest rate (as this trade effect implies a 
decrease in the inflation rate) represented through a rightward shift of MP' to MP'. Finally, the $\mathrm{AD}$ curve shifts leftwards (from $\mathrm{AD}$ ' to $\mathrm{AD}$ "), thus marginally correcting the closed economy consequences of a positive demand shock.

In the final equilibrium (point $\mathrm{C}$ ) domestic activity, inflation and interest rates have increased less that in a closed economy situation while the foreign economy (point $\mathrm{B}^{*}$ ) has benefitted from the domestic shocks. However, as reported in appendix (Table A2), the net positive impact of the shock is greater on the domestic economy than on the foreign country.

\section{A Domestic inflation Shock}

The consequences of an inflation shock in the domestic economy are depicted in figure 3. In a closed economy (Bofinger et al., 2006), the inflation shock leads to a proportional shift of the PC curve leftwards (from PC to PC'). As this creates inflation, the domestic monetary policy reaction implies an interest rate increase, so that the MP curve shifts leftwards to MP'. This shock implies an increase in inflation and a negative output gap in a closed economy situation.

In the open economy, this shock has further effects. First, it affects the foreign economy as a demand shock. It is channeled to the foreign economy through the adjustment of the terms of trade (FX) and the income consequences of the shocks on the current account of both countries. Following the increase in the domestic interest rate, the terms of trade decrease (namely, domestic currency appreciates in real terms), while the output gap becomes negative. Assuming that the expenditure switching effect related to the decrease in the terms of trade dominates the impact of the decrease in the domestic income on foreign exports, the IS* curve moves rightwards (from IS* to IS*'). This positive demand shock leads to a tightening of monetary policy in the foreign economy (an increase in the foreign interest rate) that implies a leftward shift of the MP* from MP* to MP*'. Finally, combining both effects on IS* and 
$\mathrm{MP}^{*}$, the $\mathrm{AD}^{*}$ curve shifts rightwards (from $\mathrm{AD}^{*}$ to $\mathrm{AD}^{* \prime}$ ). Thus the domestic exogenous positive demand shock implies an increase in the output gap, the inflation rate and the interest rate in the foreign economy.

[Insert Figure 3 about here]

International adjustment has a further impact in the domestic economy. As the domestic currency appreciates in real terms, exports towards the foreign economy decrease (which implies a correcting IS leftward shift from IS to IS') and, as a byproduct, a relative decrease in the domestic interest rate (as this trade effect implies a decrease in the inflation rate) represented through a rightward shift of MP' to MP'. Finally, the AD curve shifts leftward (from AD' to AD"), furthermore deteriorating the initial consequences of the inflation shock on activity.

In the final equilibrium (point $\mathrm{C}$ ) the inflation shock has worse effects of the domestic country than what should be observed for a closed economy (point B). In the meanwhile, the terms of trade adjustment leads to an increase of activity in the foreign economy at the expense of higher inflation and interest rates (points $\mathrm{B}^{*}$ and $\mathrm{B}^{*}$ ).

\section{OPTIMAL MONETARY POLICY IN A TWO COUNTRY WORLD : A NICE SITUATION}

The conduct of simple monetary rules based on interest rate manipulation cannot annihilate international spillovers coming from asymmetric supply and demand shocks. As shown in the previous section, Taylor rules may amplify the negative national consequences of the inflation shock while, they imperfectly dampen the negative effects of a demand shock at the expense of a beggar thy neighbor adjustment in the foreign country. These outcomes 
provide a simple rationale for implementing coordinated interest rate decisions between national central banks.

As underlined by Blanchard et al. (2013), the case for policy coordination rests on the principles of standard welfare economics. By taking into account cross border externalities coming from the transmission of asymmetric supply or demand shocks, the coordination of monetary policy decisions may overcome the Pareto-inefficient outcomes of unilateral interest rate decisions. Following this perspective, a cooperative setting of interest rates should naturally be addressed in a setting focusing on the conduct of optimal policy measures. As a consequence, the monetary part of the model should be modified: the Taylor rule (MP) is replaced by a loss function (L) depicting the social loss originating in the departure from the best solution characterized by price stability (ie, $\pi=0)$ and full employment $(y=0)$. Such a loss function is a standard and parsimonious way of presenting the nature of the choice faced by the central bank that implement a monetary policy to maximize social welfare. ${ }^{7}$

Adopting the standard practice of a quadratic loss function, that penalizes the squared value of the inflation rate and the output gap (with a relative weight $\chi \geq 1$ on price stability), the structure of the model used for the study of coordination issues is summarized in Table 2. For computational convenience, the IS and IS* relations have been rewritten to put all terms related to national activity on the left hand side of the relations. The PC, FE and TOT relations are kept unchanged.

[Insert Table 2 about here]

We evaluate the interest of adopting coordinated policy measures following asymmetric shocks by contrasting the non-cooperative equilibrium - where central banks minimize unilaterally their loss function - and the cooperative situation - where the two central banks minimize a joint loss function that takes into account the relative weight of each country. 


\section{Unilateral Optimal Policy Decisions (Non Cooperative Equilibrium)}

If countries set unilaterally monetary policy decisions, they minimize their loss function L (resp. $\mathrm{L}^{*}$ ) subject to their national Philips curve $\mathrm{PC}\left(\right.$ resp. $\mathrm{PC}^{*}$ ) with respect to the inflation rate and the output gap. Combining the first order conditions solving this problem, optimal monetary policy can be presented as a targeting rule measuring the social arbitrage between price stability and full employment. For the domestic economy this rule is,

$\pi=-\frac{1}{\chi \beta} y$.

This targeting rule accounts for both society's inflation reluctance $(\chi)$ and the elasticity of the inflation rate to the output gap in the Phillips curve $(\beta)$ The marginal rate of substitution between inflation and the output gap is determined by, $\frac{\partial \pi}{-\partial y}=(\chi \beta)^{-1}$, so the central bank accepts a higher increase in inflation $(\partial \pi)$ following a $1 \%$ reduction in the output gap $(-\partial y)$ when the weight associated to the objective of price stability $(\chi)$ is lower or for a lower elasticity of the inflation rate with respect to the output gap $(\beta)$.

If the central bank follows this targeting rule, the economy reaches an equilibrium that exhibits a situation of «divine coincidence» (Blanchard and Galí, 2007). In equilibrium, inflation and the output gap are only affected by supply shocks while the conduct of the optimal monetary policy is able to totally annihilate the effect of demand shocks on these two variables. However, this feature does not carry out to international variables and does not remove international spillovers following asymmetric demand and supply shock. This result (that corresponds to the equilibrium reached in a closed economy) only means that the appropriate optimal monetary policy is able to totally annihilate foreign shocks on both activity and inflation. This result is graphically discussed in figure 4 (for an asymmetric demand shock) and figure 5 (for an asymmetric inflation shock). In these figures, as we adopt the original presentation of Bofinger et al. (2005), the AD curve is replaced by the loss fuction. ${ }^{8}$ However, this 
presentation is ismorphic to the case of representing the AD curve computed on the basis of the targeting rule (in this case, the $\mathrm{AD}$ schedule is defined as $\mathrm{y}=-\chi \beta \pi$ ). Indeed, the $\mathrm{AD}$ curve crosses the initial PC curve at the bliss point A, and the other PC curves at the tangency point with the loss function (for example point B in figure 5).

The consequences of a positive demand shock (corresponding for example to a fiscal expansion) in the domestic economy are depicted in Figure 4 (and the formal results in table A4 in appendix). This shock leads to a proportional shift of the IS curve rightwards (from IS to IS'). To avoid inflation in the domestic economy, the optimal monetary policy reaction leads to an interest rate increase that closes the domestic output gap (the horizontal interest rate schedule in the domestic economic moves from $r_{o p t}$ to $\left.r_{o p t}^{\prime}\right)$. In this situation, monetary authorities are able to perfectly stabilize the inflation rate, and we get the «divine coincidence» result as with only one instrument monetary authorities are able to stabilize both the output gap and the inflation rate.

[Insert Figure 4 about here]

In the open economy, this positive domestic demand shock translates to the foreign economy through the adjustment of the terms of trade (since the income consequences of the shock is entirely neutralized by the optimal interest rate reaction of the domestic central bank). Following the increase in the domestic interest rate, the real exchange rate decreases (namely, domestic currency appreciates in real terms). This expenditure switching effect implies a shift of the IS* curve rightwards (from IS* to IS*'). As for the domestic economy, this positive demand shock leads to a tightening of monetary policy in the foreign economy that exactly closes the output gap. Finally, the foreign economy's output and inflation rate are not affected by the domestic demand shock. The terms of trade adjustment that accounts for the interest rate adjustment in the two economies is able to neutralize the international transmission of asymmetric demand shocks. 
The effect of the interest rate adjustment on the terms of trade has a further impact on the domestic economy. Since the demand shock leads to a real appreciation of domestic currency, the IS curve moves leftwards (from IS' to IS"), which creates a transitory negative output gap automatically closed by a decrease in the optimal interest rate (the horizontal interest rate schedule in the domestic economic moves from $r_{o p t}^{\prime}$ to $\left.r_{o p t}^{\prime \prime}\right)$. The final equilibrium for the domestic economy finally lies at point C. In this situation, as in the closed economy, the optimal reaction of the central bank is able to close the output gap and to keep a stable inflation rate. The main difference between the equilibrium of the closed (in point B) and the open economy (in point $\mathrm{C}$ ) lies in the value of the equilibrium interest rate, that is lower in the second case, to dampen the negative consequences of the real appreciation of the domestic on this country activity.

The consequences of a positive inflation shock in the domestic economy are depicted in Figure 5. In a closed economy, the inflation shock leads to a proportional leftward shift of the PC curve (from PC to PC'). As this creates inflation in the domestic economy, monetary policy reaction corresponds to finding the tangency point between the lowest loss function value and the new PC' curve. The new equilibrium is reached in point B. This monetary policy situation can be converted in terms of the instrument rule and corresponds to an increase in the nominal interest (the horizontal interest rate schedule in the domestic economic moves from $r_{o p t}$ to $\left.r_{o p t}^{\prime}\right)$. This shock thus leads to an increase in inflation and a negative output gap.

As usual, this domestic shock translates to the foreign economy as a demand shock. Indeed, it is channeled to the foreign economy through the adjustment of the terms of trade and the income consequences of the shocks on the current account of both countries. Following the increase in the domestic interest rate, the real exchange rate decreases (namely, domestic currency appreciates in real terms), while the output gap becomes negative. Assuming that the expenditure switching effect related to the decrease in the terms of trade dominates the 
impact of the decrease in the domestic income on foreign exports, the IS* curve moves rightwards (from IS* to IS*'). This positive demand shock (channeled through the current account) leads to an increase in the optimal interest rate that totally neutralize the effect of the domestic supply shock on the activity in the foreign economy (a further illustration of the «divine coincidence»).

[Insert Figure 5 about here]

The effect of the interest adjustment on the terms of trade has a further impact on the domestic economy. The inflation shock, by inducing an increase of domestic interest rate, leads to a real appreciation of domestic currency, the IS curve now moves leftwards (from IS to IS'), which creates a transitory negative output gap automatically closed by a decrease in the optimal interest rate. The final equilibrium for the domestic economy finally lies at point C. As for the demand shock, this open economy adjustment does not affect the equilibrium of the closed economy (in point B) except with regards to the lower value of the interest rate, that is required to dampen the negative consequences of the real appreciation of the domestic on this country activity.

Intuitively, adopting an optimal monetary policy allows the central bank to directly react to shocks rather than reacting indirectly to shocks through the observed fluctuations in the output gap and the inflation rate. In the case of a demand shock the central bank is thus able to specialize interest rate reaction on closing the output gap. This, in turn stabilizes inflation at its targeted level as both variables are positively related in the case of a demand shock.

\section{The Cooperative Solution}

If the domestic and foreign monetary authorities set their interest rate policy cooperatively, they minimize the following joint loss function: 


$$
L^{W}=\frac{1}{2}\left(L+L^{*}\right)=\frac{1}{4}(y)^{2}+\frac{\chi}{4}(\pi)^{2}+\frac{1}{4}\left(y^{*}\right)^{2}+\frac{\chi}{4}\left(\pi^{*}\right)^{2},
$$

subject to the two national Philips curves $\mathrm{PC}$ and $\mathrm{PC}$. By coordinating their monetary policy decisions, they are able to take into account the impact their national activity fluctuations on the other country activity through the income channel of international trade.

The combination of the first order conditions of this loss function lead to the following target rules, that account for the non-pecuniary externalities that act through the income channel of the current accounts:

$$
\begin{aligned}
& {[y-\chi \beta \pi]=-[y *-\chi \beta \pi *] \frac{\partial y *}{\partial y},} \\
& {[y *-\chi \beta \pi *]=-[y-\chi \beta \pi] \frac{\partial y}{\partial y *} .}
\end{aligned}
$$

Given the IS and IS* schedules in Table 2, we get $\frac{\partial y^{*}}{\partial y}=\frac{\partial y}{\partial y *}=\frac{\alpha_{3}}{1+\alpha_{3}}$. Putting this expression in the previous national target rules and combining them, the target rule for the domestic economy (the expression is the same for the foreign country) can be rewritten as:

$$
[y-\chi \beta \pi]\left[1-\left(\frac{\alpha_{3}}{1+\alpha_{3}}\right)^{2}\right]=0 .
$$

This finally degenerates to the same expression obtained for the Non cooperative equilibrium, i.e.:

$$
\pi=-\frac{1}{\chi \beta} y .
$$

Thus no further welfare gain should be expected by conducting coordinated interest rate decisions with respect to a unilateral optimal interest rate policy. Indeed, all the gains that can be obtained by monetary policy following asymmetric demand or supply shocks have already been obtained. Thus, monetary cooperation is redundant in this context. This result 
contrasts with the conventional wisdom related to the provisional gains that could be encountered by coordinating monetary policy decisions in a world with increased international financial and trade interdependences.

\section{CONCLUSION}

The financial crisis has underlined on the one side the role of financial frictions in the macroeconomy and on the other side the size of cross border spillovers through integrated markets. Studying the external consequences of monetary policy now requires a better understanding of the nature of the spillover and whether they should be accounted for in undertaking monetary decisions.

The aim of this paper was to draw on some recent progress in the presentation of New Keynesian models to provide a consistent framework that can be used in advance undergraduate courses to analyze in a compact way the issues conveyed by the question of structural and strategic interdependence in the conduct of monetary policy in an integrated world. As a contribution to the literature, we have shown that this question can be presented through the use of interest rate rules rather than the use of money supply decisions, as it is the case in Mundell-Fleming models generally used to discuss this major issue of international macroeconomic questions. We have used a thoroughly graphical approach to analyze the question at hands.

The static model introduced in this paper has underlined how asymmetric demand and supply shock create international spillovers combining pecuniary (terms of trade fluctuations) and non-pecuniary (income effects) externalities that affect trade relation between countries and may create beggar thy neighbor situations. The decision to coordinate interest rate decisions may thus appear as a natural concern for the authorities. As the 
question of the coordination of interest rate decisions is related to welfare issues, it has been addressed in a setting focusing on the conduct of optimal policy measures. We show in a simple way that under optimal interest rate rules the Non cooperative and cooperative solutions are isomorphic. As a consequence, there is no incentive to coordinate monetary policy actions and the Non cooperative equilibrium can be considered as reflecting the fact that the international monetary system is operating Near an Internationally Cooperative Equilibrium (NICE) situation.

This paper should be considered as a first step to introduce state of the art considerations in the teaching of monetary policy coordination. Indeed, our framework provides the basis for possible extensions to account for new factors that may favor situations where cooperation improves the equilibrium outcome. We leave open for future investigation the introduction of financial frictions (Poutineau and Vermandel, 2015) or the Zero Lower Bound question (Buttet and Roy, 2014). 


\section{REFERENCES}

Blanchard, O., and J. Galí. 2007. Real Wage Rigidities and the New Keynesian Model. Journal of Money, Credit, and Banking, 39(1): 35-65.

Blanchard O., J. Ostry. and A. Gosh. 2013. Overcoming the obstacles to international macro policy coordination is hard, vox.eu, December, http://voxeu.org/article/obstaclesinternational-macro-policy-coordination.

Bofinger, P., E. Mayer, and T. Wollmershäuser. 2006. The bmw model: a new framework for teaching monetary economics. The Journal of Economic Education, 37(1): 98-117.

Bofinger, P., E. Mayer, and T. Wollmershäuser. 2009. Teaching New Keynesian Open Economy Macroeconomics at the Intermediate Level The Journal of Economic Education, 40(1): 80-102.

Buttet S. and U. Roy. 2014. A Simple Treatment of the Liquidity Trap for Intermediate Macroeconomics Courses The Journal of Economic Education, 45(1): 36-55.

Carlin W. and D. Soskice. 2015. Macroeconomics, Institutions, Instability and the Financial System, Oxford University Press

Coeuré B. 2016. The internationalization of monetary policy, Journal of International Money and Finance 67 (5): 8-12

Daniels J. and D. Van Hoose. 1998. Two-Country Models of Monetary and Fiscal Policy: What Have We Learned? What More Can We Learn? Open Economies Review, 9(3): 265284.

Engel, C. 2016. International Coordination of Central Bank Policy. Journal of International Money and Finance, 67: 3-24.

Debortoli D., J. Kim, J. Lindé and R. Nunes. 2017. Designing a Simple Loss Function for Central Banks: Does a Dual Mandate Make Sense? IMF working paper.

Feenstra R. and A. Taylor. 2017. International Macroeocnomics. Worth Publishers. 
Frankel J. 2016. International Coordination in Policy Challenges in a Diverging Global Economy. Federal Reserve Bank of San Francisco, 41-77.

Gali, J and T. Monacelli., 2005. Monetary Policy and Exchange Rate Volatility in a Small Open Economy, Review of Economic Studies 72: 707-734.

Ostry, J D and A Ghosh. 2016. On the Obstacles to International Policy Coordination Journal of International Money and Finance, 67: 25-40.

Oudiz, G and J Sachs. 1984. Macroeconomic Policy Coordination among Industrial Economies, Brookings Papers on Economic Activity 1: 1-75.

Poutineau J.C. and G. Vermandel. 2015. A primer on Macro prudential Policy, Journal of Economic Education, 02/2015; 46(1):68-82.

Taylor, J. 1993. Discretion versus Policy Rules in Practice. Carnegie-Rochester Conference Series on Public Policy. 39: 195-214.

Taylor J. 2013. International monetary policy coordination: past, present and future, $B I S$ Working Papers No 437 December

Gartner M. 1993. Macroeconomics under flexible exchange rates, LSE handbooks in Economics, Harvester Wheatsheaf, London.

Woodford M. 2003. Interest and Prices: Foundations of a Theory of Monetary Policy, Princeton University Press 


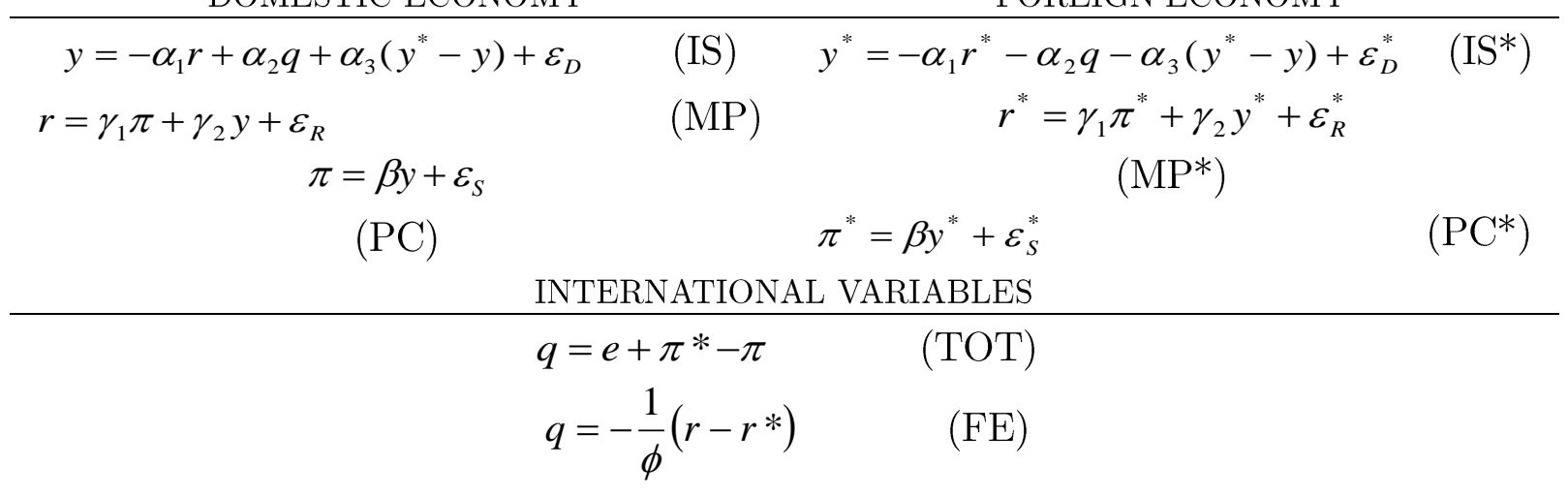

TABLE 1 : The model economy with a Taylor rule.

$$
\begin{array}{cc}
y=\frac{-\alpha_{1}}{1+\alpha_{3}} r+\frac{\alpha_{2}}{1+\alpha_{3}} q+\frac{\alpha_{3}}{1+\alpha_{3}} y^{*}+\frac{1}{1+\alpha_{3}} \varepsilon_{D} & y^{*}=\frac{-\alpha_{1}}{1+\alpha_{3}} r^{*}-\frac{\alpha_{2}}{1+\alpha_{3}} q+\frac{\alpha_{3}}{1+\alpha_{3}} y+\frac{1}{1+\alpha_{3}} \varepsilon_{D}^{*} \\
L=\frac{1}{2} y^{2}+\frac{\chi}{2} \pi^{2} & L^{*}=\frac{1}{2} y^{* 2}+\frac{\chi}{2} \pi^{* 2} \\
\pi=\beta y+\varepsilon_{S} & \pi^{*}=\beta y^{*}+\varepsilon_{S}^{*} \\
\text { INTERNATIONAL VARIABLES }
\end{array}
$$

$$
\begin{gathered}
q=-\frac{1}{\phi}\left(r-r^{*}\right) \\
q=e+\pi^{*}-\pi
\end{gathered}
$$

TABLE 2 : The model economy with an optimal interest rate rule. 


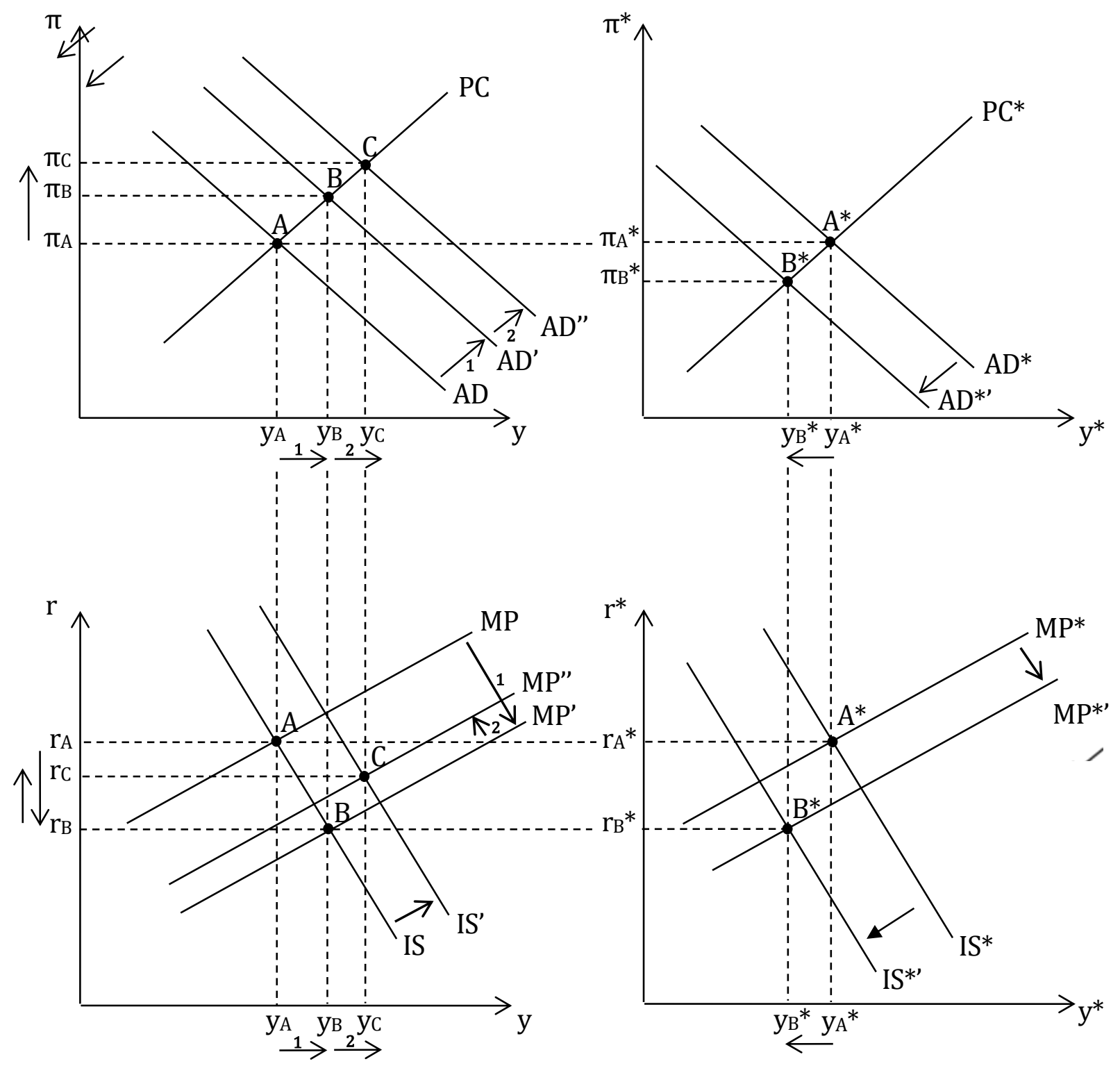

FIGURE 1 : Consequences of an exogenous decrease of the domestic interest rate 


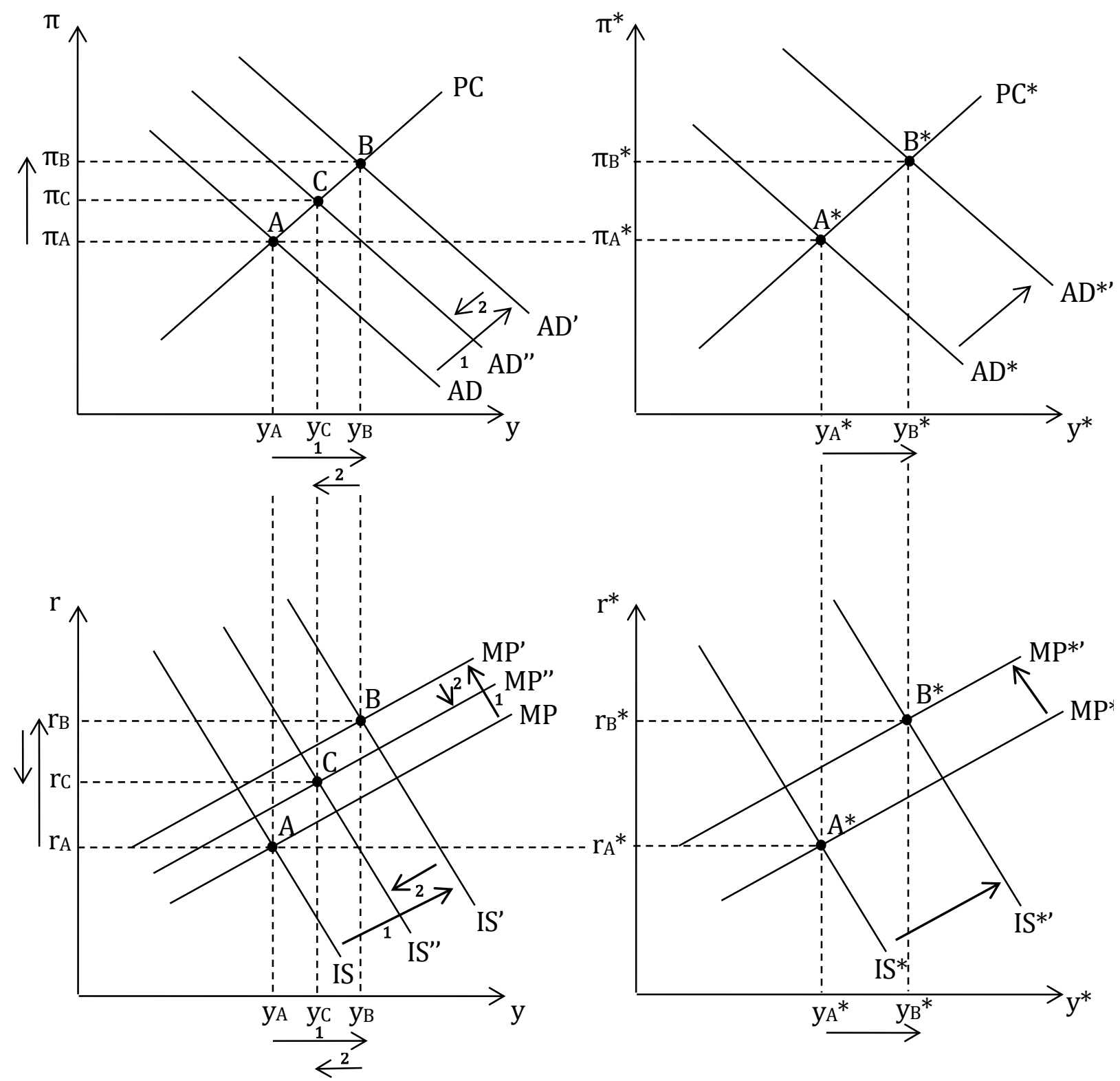

FIGURE 2 : Consequences of a positive demand shock (simple interest rate rule). 

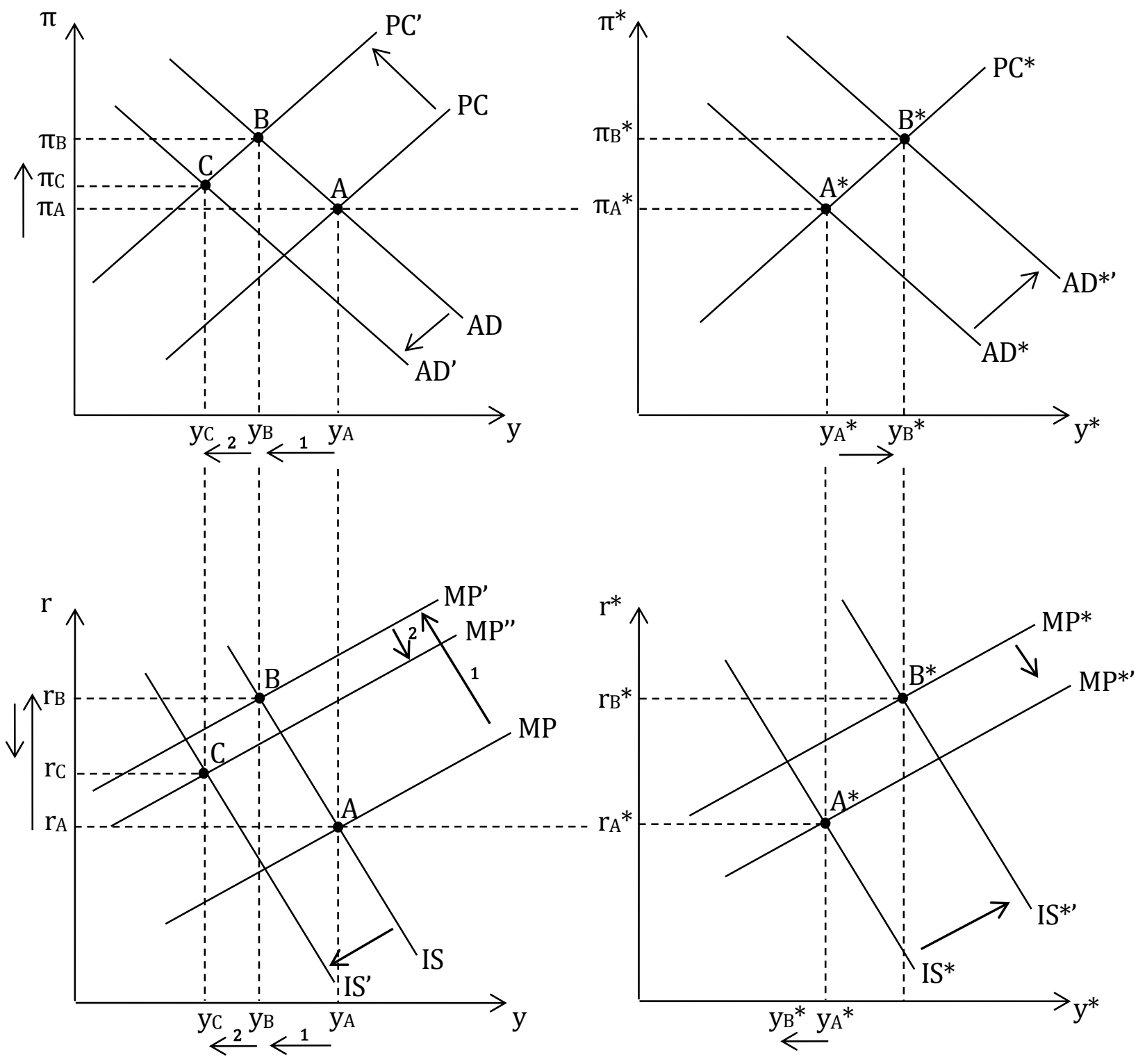

FIGURE 3 : Adjustment to an inflation shock (simple interest rate rule). 

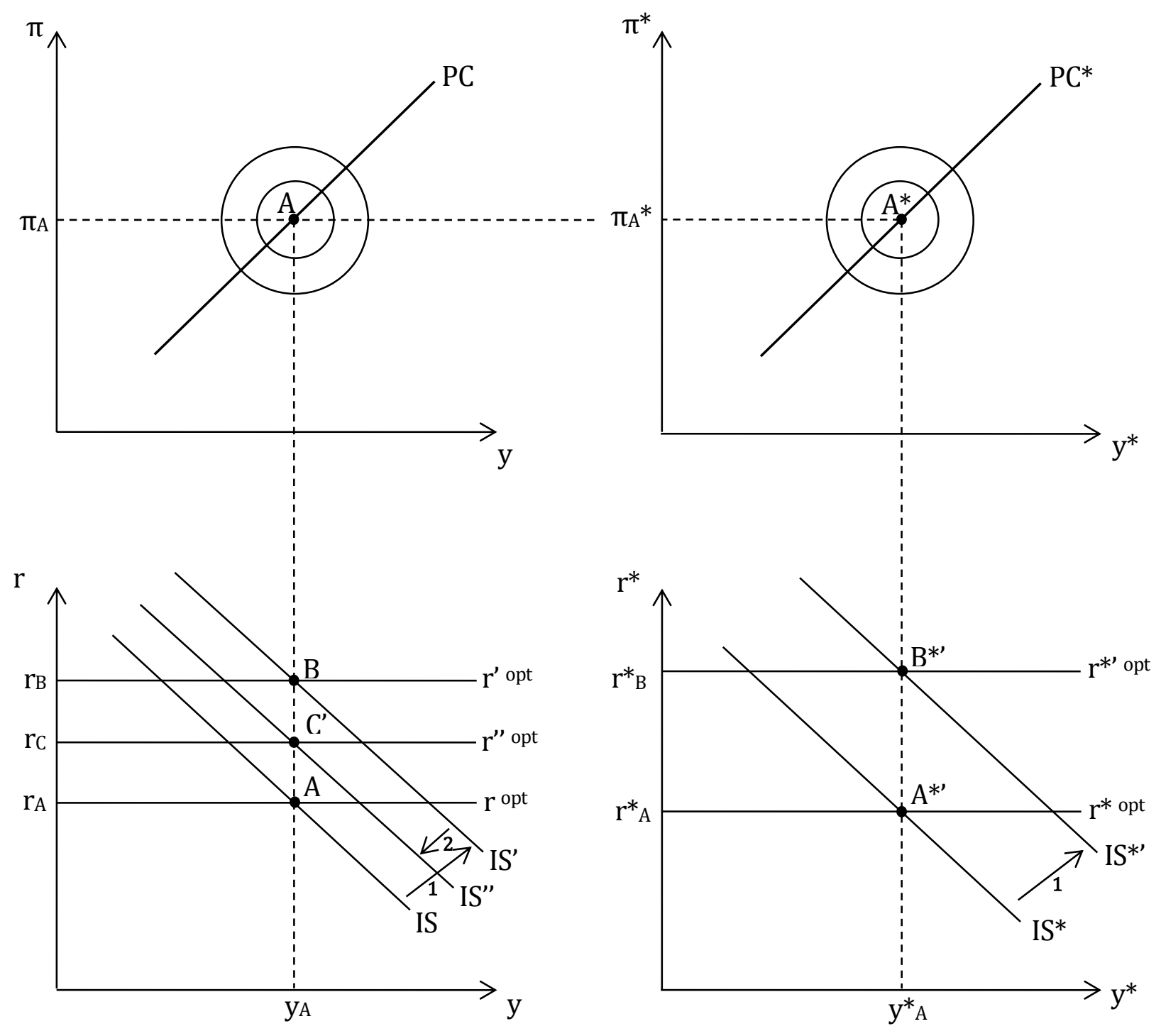

FIGURE 4 : The consequences of a positive demand shock (optimal interest rate rule). 


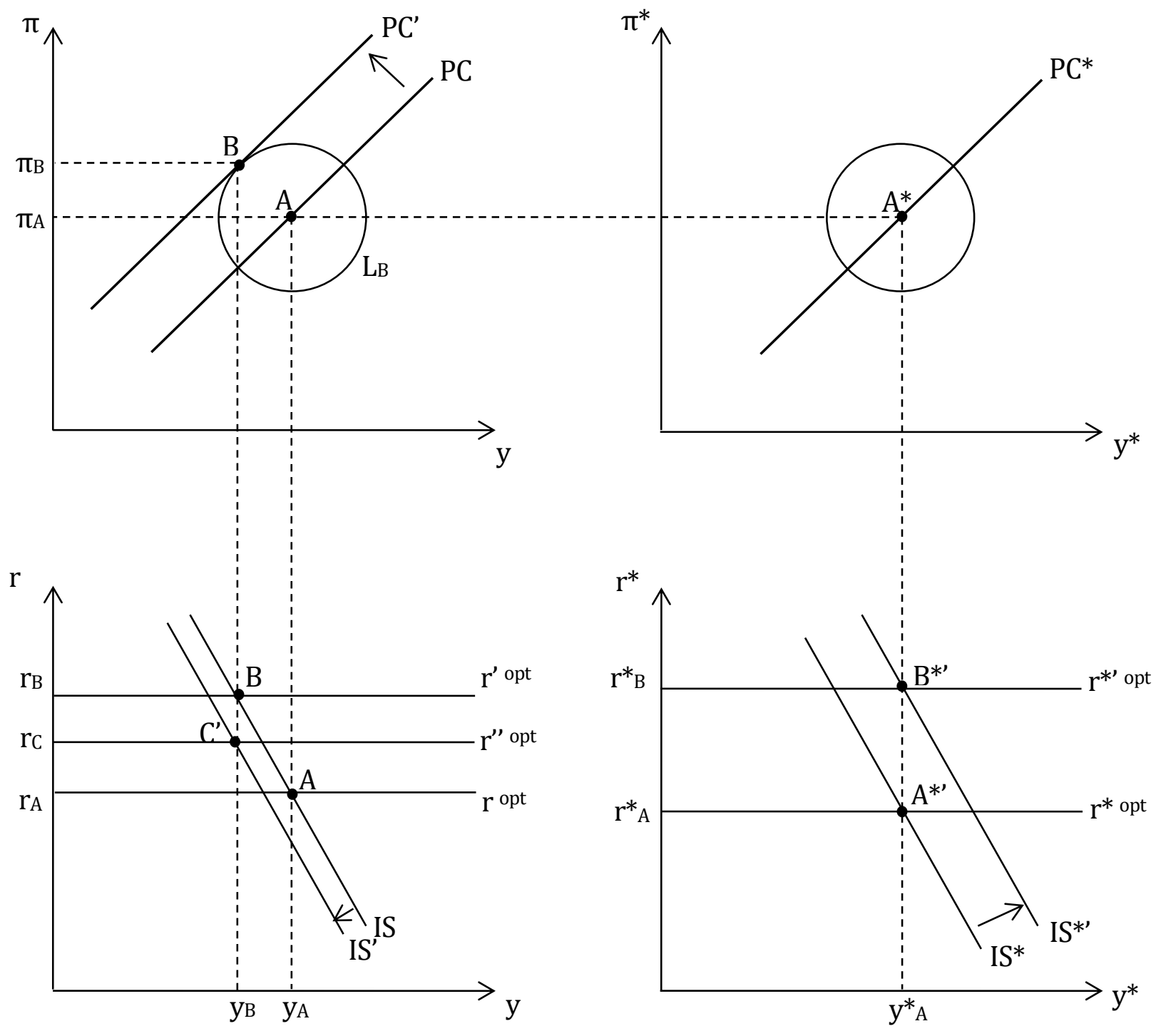

FIGURE 5 : Adjustment to an inflation shock (optimal interest rate rule) 


\section{NOTES}

${ }^{1}$ An alternative story is provided by Oudiz and Sachs (1984) where coordination issues arise from a disinflation game between two countries. The economic rationale for international monetary policy coordination stems from the presence of non-pecuniary externalities in the conduct of national monetary policy. The explanation is cast in the following terms: By appreciating the exchange rate each country seeks to "export" inflation. Since in equilibrium, they cannot both appreciate, the Nash equilibrium is characterized by overly tight monetary policy and a correspondingly large output gap and unemployment. Under cooperation, they do not engage in this futile game, and inflation is a bit higher but unemployment lower.

${ }^{2}$ As underlined by John Taylor (2013), "Empirical research beginning in the early 1980s predicted that the gains from international coordination of monetary policy would be quantitatively small compared to those achieved from each central bank following a monetary policy which optimized its own country's economic performance. (...) By choosing policies that worked well domestically attempts to formally coordinate policy choices across countries would probably have added little to macroeconomic stability during the Great Moderation. (...) The international monetary system was operating near an internationally cooperative equilibrium (NICE)".

${ }^{3}$ An extended version of the paper provides a companion analysis in a two country version of the small open economy model provided by Carlin and Soskice (2015, chapter 9). It is available at the following address: https://sites.google.com/view/poutineau/research

${ }^{4}$ Incorporating fiscal policy along the lines of Bofinger et al. (2006) is a straightforward extension of the model for treating questions related to the implementation of fiscal policy in an integrated world. This extension (not covered here) can be done easily to assess the contribution of fiscal policy decisions to current account fluctuations.

${ }^{5}$ Gärtner (1993).

${ }^{6}$ This effect is similar to the one observed in the Mundell-Fleming model following an increase in the domestic money supply. Assuming that the foreign country does not match the domestic country policy, its currency appreciates in real terms relative to the domestic country's, thereby reducing its exports via the expenditure switching effect. Thus fluctuations in the terms of trade act as a pecuniary externality between countries, following unilateral interest rate manipulations.

${ }^{7}$ As underlined by Debortoli et al. (2017), describing the objectives of central banks using a loss function combining inflation and the output gap is a parsimonious way of approximating social welfare, as banks are typically subject to a mandate involving only a few variables. Woodford (2003), provides a proof of the correspondence of the loss function 
and the maximization of social welfare. Noticeably, solving the central bank program gives rise to a targeting condition representing its relative concern between stabilizing inflation and activity reflecting its mandate. However, the operational policy instrument (the short run interest rate) is computed using this targeting rule. For a recent quantitative illustration of this approach using a loss function to characterize the Fed policy see Debortoli et al. (2017).

8 Assuming the same weight on inflation and output this loss function is a circle centered on the bliss point where $\mathrm{L}=0$. 